\title{
MULTI-PRODUCT MULTI-PERIOD INVENTORY ROUTING OPTIMIZATION WITH TIME WINDOW CONSTRAINS
}

\author{
Xiao, N. ${ }^{* * *} \&$ Rao, Y. L.** \\ *School of Economics, Shenzhen Polytechnic, Shenzhen, Guangdong 518055, China \\ ${ }^{* *}$ Business School, Central South University, Changsha, Hunan 410083, China \\ E-Mail: catherine842@sina.com
}

\begin{abstract}
The concept of the green supply chain leads to the recent expansion of the green logistics investigation. Under the mode of VMI (vendor managed inventory), integrating the inventory and routing of the supplier and the customer as a whole is vital to achieve the optimization of total distribution cost in distribution logistics systems. In this paper, the inventory routing problems on a two-echelon logistics system composed of a single distribution centre and multiple customers for multi-product in multi-period with time constrains is studied under the conditions of VMI strategy. Both inventory costs and distribution costs are considered in the logistics system, and an improved fuzzy genetic algorithm is proposed to solve the optimization model of IRP (inventory routing problems) for multi-product in multi-period with time constrains. It has been proved that the proposed algorithm is a very efficient approach for the IRPs. Finally, the effectiveness of the proposed algorithm and the optimization model are demonstrated through simulation of computational experiments.

(Received, processed and accepted by the Chinese Representative Office.)
\end{abstract}

Key Words: IRP (Inventory Routing Problems), VMI (Vendor Managed Inventory), Fuzzy Genetic Algorithm, Multi-Product, Multi-Period

\section{INTRODUCTION}

The problems of climate change and greenhouse gas emissions are increasingly becoming a focus of attention in most societies. In response to this challenge, an increasing number of companies are taking actions to reduce their carbon emissions by using environmentally friendly low carbon production methods [1-4]. These green principles are also applied to the supply chain [5-8], including green logistics investigation [9-12].

One of the well-known topics typically addressed in this regard is the inventory routing problem (IRP) which considers the integrated inventory routing optimization process with the mode of vendor managed inventory (VMI) [13]. However, most of the recent related research studies the models without consideration of the time window constrains, which are essential in meeting the requirements of the customers.

This paper is an attempt to study the multi-product multi-period inventory routing problem with time window constrains. The reminder of the paper is organized as follows. Section 2 introduces the related literature about VMI and the IRP. Section 3 describes the problem in detail. Section 4 presents the mathematic model, followed by the introduction of the proposed hybrid algorithm for solving the model. Section 5 presents the simulation experiment and the experimental results. Finally, conclusions are discussed along with the related managerial implications.

\section{LITERATURE REVIEW}

Transportation and inventory management are two key logistic drivers of supply chain management. The coordination of these two drivers, often known as the IRP, is typically the issue at hand in vendor-managed inventory systems (VMI) $[14,15]$. Papers $[16,17]$ presented a comprehensive literature review regarding IRPs. They can be broadly categorized according 
to the following criteria: finite or infinite planning horizons $[16,18]$, single or multi-period [19], single or multi-customer [20, 21], single or multi-product [22], identical or non-identical vehicles [23], and deterministic or stochastic demand [24]. Several other variants of IRPs can also be found, such as IRPs with direct deliveries [25] or with transshipment options [26-28].

Research on inventory and integrated transportation optimization developed early. In the late $1980 \mathrm{~s}$, a contradictory problem of inventory and transportation was proposed by Federgruen and Zipkin for the first time [29], and from then this issue gradually become the focus of many scholars.

A multi-logistics network was researched by Burns et al., which determined the minimum cost of inventory and transportation [30]. They assumed that customer requirements were fixed. By analysing and comparing the two different distribution strategies the following conclusions are reached. The first strategy is that each time the vehicle delivers goods directly to a certain point of demand; the second strategy is a roving vehicle delivery for various needs. The customers are divided into several delivery regions and each region reachable to the customers by a car has the same frequency of distribution. The results show that with an increase in the value of goods, transportation distance, density of customers, and the cost of inventory holding, the second strategy is more efficient than the first one.

It is assumed that the system has only one distribution centre, and each retailer gets the products at a fixed rate. A number of complex factors such as deterministic demand, single product, time continuous inventory and vehicle routing optimization was considered in the study of Anily and Federgruen [31]. They set up the optimized cost model of average inventory and transportation. The process is grouping the customers according to the demand, arranging the vehicle to its services, and then determining the optimal order cycle of each customer in each group. This is the optimal inventory policy and dispatch plan.

The distribution system of a single supplier and a single retailer under stochastic demand was researched by Ernst and Pyke [32]. They established the model considering both inventory and transportation costs, and designed an algorithm to determine the supplier's and the retailer's optimal inventory policy and the optimal expected replenishment cycle length. Chandra and Fisher researched the distribution network inventory and transportation integrated optimization model of a single product [33]. The paper verified the advantages of inventory control and transportation with mutual cooperation and through the analysis of the specific example, the cooperation resulted in a large savings.

Speranza and Ukovich established the single point to single point scattered determined model of the distribution system, and the objective was to determine expected distribution frequency for each product [34]. They found distribution frequency by sharing a vehicle is the best distribution strategy. Viswanathan and Mathur presented the distribution system consisting of one supplier and multiple customers, and a heuristic algorithm was designed to determine the requirements of various products [35]. Through this algorithm, the delivery quantity and distribution strategy of the average total cost of inventory and transportation in the distribution system over a long period of time are obtained.

Herer and Roundy designed a polynomial time heuristic algorithm, and in the research based on the traveling salesman problem, they integrated optimization of inventory and transportation in a multi distribution system [36]. The issue of customer supply with a vehicle at different times within a limited time range from a single supplier was studied by Bertazzi \& Speranza, based on the assumption that each customer demand is fixed and does not allow running out of stock [15]. 


\section{PROBLEM DESCRIPTION}

\subsection{VMI Logistics system}

The IRP under VMI mode is studied in this paper. Different from previous literature, the product characteristics at different stages of a life cycle are taken into the consideration, as well as the time window constrains. The problem can be described as follows. The logistics system is composed of one supplier and multiple customers. The temporary distribution centres are established by the supplier in the regions which are responsible for transiting goods to each customer without having control over the inventory. The supplier can supply multiple products for the customers at the same time, and be responsible for the unified management of the inventory and the distribution according to the characteristics of the product in different life cycle stages. The goods are distributed to all customers from the regional temporary transfer centres after the temporary custody, sorting, distribution and other operations. The vehicles are available from the car depots instead of the temporary distribution centre. All vehicles in the depots can be allocated by the supplier, but they should return to the depots after the distribution. The composition of the logistics system is shown in Fig. 1.

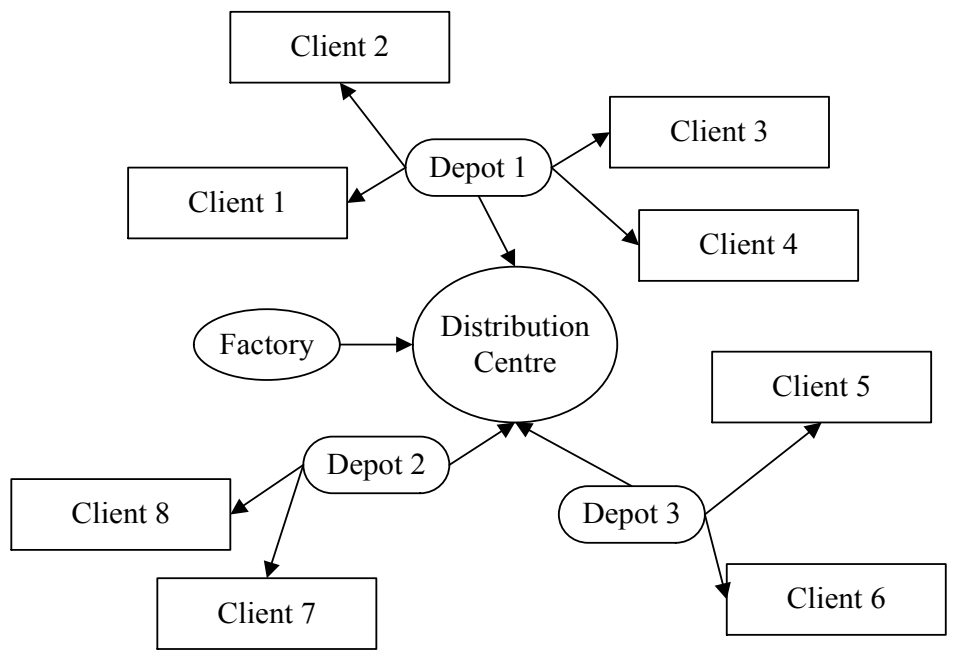

Figure 1: The composition of logistics system (the arrow represents the service relationship).

Under the mode of VMI, the inventory information is shared among the supplier and the customers, so the supplier can monitor the inventory level for each customer regularly, and then accurately predict the rate of customer demand. Therefore, the supplier needs to consider both the inventory cost and delivery cost in the logistics system, and determine the optimal distribution plan with the minimal total cost and ensure a good level of customer service.

Under the mode of VMI, if the supplier intends to reduce the inventory cost, the inventory will be reduced. However, the inventory reduction will lead to an increase in frequency and costs of distribution in order to maintain a high level of service. If the supplier seeks to lower distribution costs, it will result in the fewer occurrences of distribution and more distribution amount each time, which will lead to the increase of inventory and inventory costs.

The IRP should consider inventory control, logistics and distribution as a whole, and balance the inventory cost and distribution cost. It also must determine the frequency of distribution, vehicle allocation and transportation routing plan which will result in the minimum level of total costs of the whole logistics system. The managers shall make decisions on the three main problems as follows:

(1) Distribution frequency or delivery time. When the period length has been confirmed, the supplier must determine when to provide distribution services for which customers. When 
the planned period length has not been determined, the supplier must determine frequency distribution for the customers during the period.

(2) Distribution amount. The supplier must identify the distribution amount of various kinds of goods for each customer to meet the requirement of the customers and with a high level of service.

(3) Modes of transportation. The supplier must identify the modes of transportation (e.g. one carload transport, less-than-one carload transport or a combination of these two modes). When less-than-one carload transport is employed, the supplier must decide how to arrange delivery routes for different customers.

\subsection{Cost of logistics system}

(1) The inventory costs

Inventory costs refer to the related costs to ensure inventory system operations, which is the basis of inventory management decisions. It mainly includes the ordering costs, inventory holding costs and shortage costs. Since this paper assumes there are one supplier and multiple customers in the logistics system, the transport costs from factory to the distribution centre can be recognized as the ordering costs, inventory costs of each customer can be recognized as inventory holding costs, the shortage cost of the customer can be recognized as the shortage cost.

(2) The distribution costs

Distribution is an important aspect of the logistics, referring to the sum of expenses including stock, tally, and delivery in the process of logistics distribution. The distribution costs include shipping transportation cost, handling cost, packaging cost, sorting and distribution costs and circulation processing cost, etc., depending on the different functions of distribution activities.

\section{MATHEMATICAL MODEL}

\subsection{Hypothesis}

The IRP optimization is very complicated due to many affecting factors and constrains. The assumptions of the mathematical model are as follows based on the practical logistics system:

(1) The planning period of the system is fixed; i.e., a quarter or a year. Each item in a planning period only has one lifecycle.

(2) The supplier can provide multiple products. The transportation costs are calculated by weights of the products at a fixed rate.

(3) The customer demand rates can be for different products or in different stages of their life cycles.

(4) Out of stock inventories is not allowed, which means that the out of stock cost is infinite.

(5) The locations of the distribution centres, depots and the customers are known and fixed.

(6) The distribution centres are established by the supplier in the regions which are responsible for transiting goods to each customer without the supplier having control over the inventory.

(7) There is no vehicle in distribution centre. All vehicles are from depots and eventually return to the depots after the distribution tasks.

(8) One vehicle can service several clients at the same time, but one customer can only be served by one vehicle. 
(9) All products can be mixed loading, so the vehicle capacity constraint is only considered when loading. The capacities of the various vehicles are the same.

(10) The distribution centres, depots and the customers all have their own operating time, so the vehicles must distribute the products during the operating time.

\subsection{Defined variables}

The variables used in the model are shown as follows:

$D$ - number of the depots, $d=1,2, \ldots, D$ denotes the depot, $d=0$ denotes the distribution centre;

$K \quad$ - number of the vehicles in the depots, $k=1,2, \ldots, K$ denotes the vehicle;

$N$ - number of the customers, $n=1,2, \ldots, N$ denotes the customer;

$P \quad$ - type number of the products, $p=1,2, \ldots, P$ denotes the product;

$S_{\text {tnp }}$ - the demand for $p$ of the customer $n$ in stage $t, t=1,2,3, t=1$ introduction period, $t=2$ growth period, $t=3$ mature period;

$S_{t p}-$ the demand of the product $p$ in stage $t, S_{t p}=\sum_{n=1}^{N} S_{t n p}$;

$Q_{t n p}$ - the distribution amount of product $p$ for customer $n$ in stage $t$;

$C_{f}$ - the fixed costs from the factory to the distribution centre per trip;

$C_{p}$ - the transportation costs of unit product from the factory to the distribution centre;

$C_{d}$ - the fixed costs of the distribution centre for each distribution;

$C_{r} \quad$ - the fixed costs of a single task;

$C_{l}$ - the unit distance costs of the driving vehicles (not related to the loading capacity);

$l_{i j} \quad$ - the distance from note $i$ to note $j$; note refers to the factory, distribution centre or the customers;

$C_{n p}$ - the unit inventory costs for product $p$ of customer $n$ during the planning period;

$W_{p}$ - the weight of product $p$;

$W$ - maximum vehicle loading capacity;

$V_{t}^{d k}-$ maximum tasks for vehicle $k$ in depot $d$ in period $t$;

$T C_{1}$ - the transit cost from factory to distribution centre;

$T C_{2}$ - the holding costs;

$T C_{3}$ - the distribution costs, where the transportation costs is denoted by $T C_{v}$;

$T C$ - the total costs of the time period;

$V \quad$ - average speed of the vehicles;

$T S_{i}$ - the earliest start time of note $t$;

$T F_{i}$ - the latest end time of note $t$;

$T_{i}^{d k}$ - the arrival time to note $t$ of vehicle $k$ in depot $d$.

The decision variable of the model is defined as following:

$x_{i j}^{d k}=\left\{\begin{array}{l}1, \text { the vehicle } k \text { of depot } d \text { travel from node } i \text { to node } \mathrm{j}, \\ 0, \text { others, }\end{array}\right.$

$\mathrm{y}_{i}^{\mathrm{dk}}=\left\{\begin{array}{l}1, \text { note } i \text { is visited by vehicle } \mathrm{k} \text { of depot } \mathrm{d}, \\ 0, \text { others, }\end{array}\right.$

\subsection{Cost calculation}

According to the analysis in section 3.2, the total costs of the system include the transfer costs from factory to distribution centre, distribution costs and inventory costs. The objective of the IRPs is to minimize the costs in the entire life cycle with a reasonable inventory and 
distribution strategy, to fully meet the needs of customers. The objective function is:

$$
\min T C=T C_{1}+T C_{2}+T C_{3}
$$

The transfer costs from factory to distribution centre include factory fixed costs of each distribution and the transportation costs from the factory to the distribution centre:

$$
T C_{1}=\sum_{t=1}^{T} \sum_{n=1}^{N} \sum_{p=1}^{P} \frac{S_{t n p}}{Q_{t n p}} \cdot C_{f}+\sum_{t=1}^{T} \sum_{n=1}^{N} \sum_{p=1}^{P} S_{t n p} \cdot C_{p}
$$

Since the demand rates are different in the different periods, the holding costs of the customers can be expressed as:

$$
T C_{2}=\frac{1}{2} \sum_{t=1}^{T} \sum_{n=1}^{N} \sum_{p=1}^{P} Q_{t n p} \cdot C_{n p}
$$

Distribution costs can be divided into the fixed costs of distribution and transport costs, which are:

$$
T C_{3}=\left(\sum_{t=1}^{T} \sum_{n=1}^{N} \sum_{p=1}^{P} \frac{S_{t n p}}{Q_{t n p}}+\sum_{d=1}^{D} \sum_{k=1}^{K} y_{0}^{d k}\right) \cdot C_{r}+\sum_{d=1}^{D} \sum_{k=1}^{K} \sum_{j=1}^{D+N} \sum_{i=1}^{D+N} x_{i j}^{d k} \cdot l_{i j} \cdot C_{l}
$$

\subsection{Model function}

The mathematical models are established as follows:

$$
\begin{gathered}
\min T C=\sum_{t=1}^{T} \sum_{n=1}^{N} \sum_{p=1}^{P} \frac{S_{t n p}}{Q_{t n p}} \cdot C_{f}+\sum_{t=1}^{T} \sum_{n=1}^{N} \sum_{p=1}^{P} S_{t n p} \cdot C_{p}+\frac{1}{2} \sum_{t=1}^{T} \sum_{n=1}^{N} \sum_{p=1}^{P} Q_{t n p} \cdot C_{n p} \\
+\left(\sum_{t=1}^{T} \sum_{n=1}^{N} \sum_{p=1}^{P} \frac{S_{t n p}}{Q_{t n p}}+\sum_{d=1}^{D} \sum_{k=1}^{K} y_{0}^{d k}\right) \cdot C_{r}+\sum_{d=1}^{D} \sum_{k=1}^{K} \sum_{j=1}^{D+N} \sum_{i=1}^{D+N} x_{i j}^{d k} \cdot l_{i j} \cdot C_{l} \\
\quad \sum_{d=1}^{D} \sum_{k=1}^{K} y_{i}^{d k}=1, i=1,2, \ldots, N \\
\sum_{i=1}^{N} x_{0 i}^{d k}=\sum_{i=1}^{N} x_{i 0}^{d k}, k=1,2, \ldots, K, d=1,2, \ldots, D \\
\sum_{i=1}^{N} x_{0 i}^{d k} \leq V_{t}^{d k}, \quad k=1,2, \ldots, K, d=1,2, \ldots, D, t=1,2,3 \\
\sum_{j=1}^{N} x_{i j}^{d k}=\sum_{j=1}^{N} x_{j i}^{d k}=y_{i}^{d k}, i=1,2, \ldots, N, k=1,2, \ldots, K, d=1,2, \ldots, D \\
\sum_{i=1}^{N} \sum_{p=1}^{P} Q_{t i p} \cdot W_{p} \cdot y_{i}^{d k} \leq W \\
T_{i}^{d k}=\sum_{j=1}^{N} T_{j}^{d k} \cdot x_{j i}^{d k}+\frac{l_{i j}}{V}, k=1,2, \ldots, K, d=1,2, \ldots, D \\
T S_{i} \leq T_{i}^{d k} \leq T F_{i}, i=1,2, \ldots, N, k=1,2, \ldots, K, d=1,2, \ldots, D \\
x_{i j}^{d k}, y_{i}^{d k} \in\{0,1\}, \quad i=0,1, \ldots, N+D, \quad j=0,1, \ldots, N+D, k=1,2, \ldots, K, d=1,2, \ldots, D
\end{gathered}
$$

Eq. (5) is the objective function. Eq. (6) indicates when each customer can only be visited once by one vehicle. Eq. (7) indicates when all vehicles are from depots and eventually return to the depots after the distribution tasks. Eq. (8) limits the number of vehicles available in 
period $t$ to a given quantity. Eq. (9) ensures that all the customers are served. Eq. (10) limits the capacity of the vehicle. Eqs. (11) and (12) limit the time window constrains. Eq. (13) limits values of the decision variables.

\section{IMPROVED FUZZY GENETIC ALGORITHM}

In this study, we propose an adaptive fuzzy logic-based genetic approach. As the approach's major novelty, an adaptive-fuzzy logic module is integrated with the conventional GA (genetic algorithm) in an attempt to improve the performance of the GA and reduce the premature convergence problem by adjusting the algorithm's parameters.

\subsection{Design of GA}

(1) Encoding.

Generally speaking, a chromosome is a binary digits sequence, representing a solution to the problem domain. A portion of the chromosome is known as its genes and is mapped to the portion of the solution. The Binary digit encoding method is employed, and the binary digit encoding of two depots and ten customers is shown in Fig. 2.

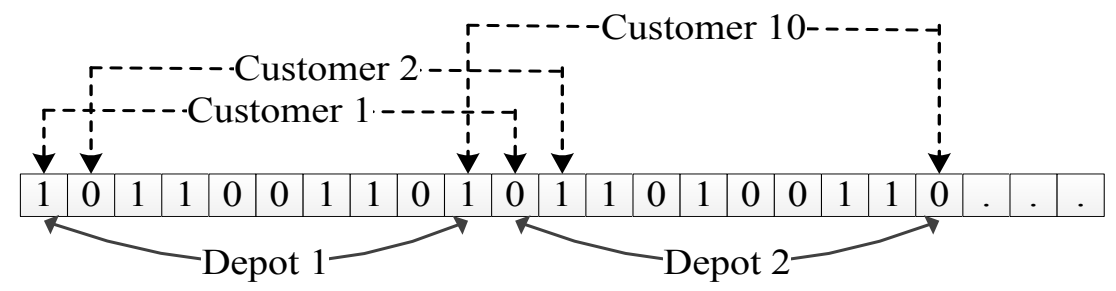

Figure 2: Binary digit encoding.

(2) Fitness function.

A new fitness function is proposed as follows:

$$
T C_{\max } /\left(T C_{1}+T C_{2}+T C_{3}\right)
$$

$T C_{\max }$ is the maximum value of Eq. (5).

(3) Selection operator.

Two individuals are selected randomly and then the fittest one is selected to reproduce.

(4) Crossover operator.

The order of the crossover operator is shown in Fig. 3.

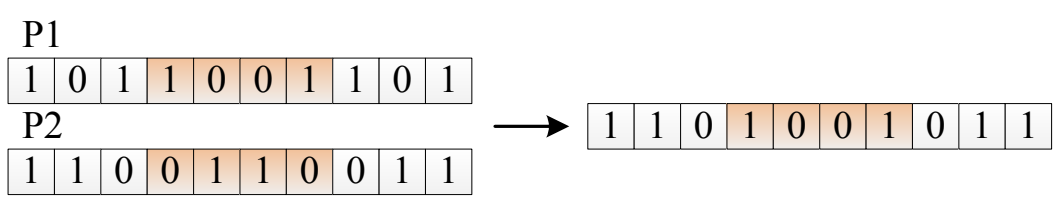

Figure 3: Crossover operator.

(5) Mutation operator.

Invert mutation: Two positions are selected randomly in the string and then the order is reversed as shown in Fig. 4.

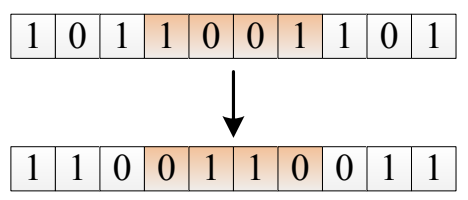

Figure 4: Mutation operator. 


\subsection{Adaptive-fuzzy logic module}

The output parameter is the mutation probability, and the input parameters are shown in Table I.

Table I: Input parameters of fuzzy logic module.

\begin{tabular}{|c|l|}
\hline Input parameter & \multicolumn{1}{|c|}{ Parameter explanation } \\
\hline$\Delta \bar{F}$ & The range of the average fitness value, $\Delta \bar{F}=\frac{\left(\overline{F_{r}}-\overline{F_{r-1}}\right)}{\overline{F_{r-1}}}, \Delta \bar{F} \in[0,1], r>1$ \\
\hline$\alpha$ & $\begin{array}{l}\text { The gap of the fitness value between the current chromosome and the best } \\
\text { chromosome, } \alpha=\frac{\left(F_{\max }-F\right)}{\left(F_{\max }-F_{\min }\right)}, \alpha \in[0,1]\end{array}$ \\
\hline
\end{tabular}

$F \quad$ - fitness of current chromosome,

$\overline{F_{r}} \quad$ - average fitness of $\mathrm{r}$ generation population,

$F_{\max }-$ fitness of the best chromosome of current population,

$F_{\min }$ - fitness of the worst chromosome of current population.

The triangle membership function is used in this paper, and the graphic of membership function is shown in Fig. 5.

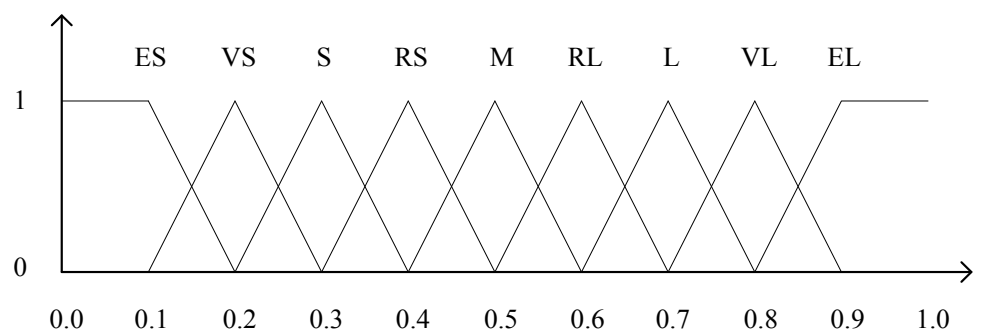

Figure 5: The membership function graphic of input and output parameter.

Table II shows the fuzzy logic rules of mutation probability.

Table II: The fuzzy logic rules of mutation probability.

\begin{tabular}{|c|ccccccccc|}
\hline$\Delta \vec{F}(t)$ & ES & VS & S & RS & M & RL & L & VL & EL \\
\hline ES & M & RL & RL & L & L & VL & VL & EL & EL \\
VS & RS & M & RL & RL & L & L & VL & VL & EL \\
S & RS & RS & M & RL & RL & L & L & VL & VL \\
RS & S & RS & RS & M & RL & RL & L & L & VL \\
M & S & S & RS & RS & M & RL & RL & L & L \\
RL & VS & S & S & RS & RS & M & RL & RL & L \\
L & VS & VS & S & S & RS & RS & M & RL & RL \\
VL & ES & VS & VS & S & S & RS & RS & M & RL \\
EL & ES & ES & VS & VS & S & S & RS & RS & M \\
\hline
\end{tabular}

\section{EXPERIMENTAL}

In this paper, the logistics service system of an electronic product company was chosen as an example of empirical analysis. This company is a manufacturer of medium-sized electronic products in a particular province, and their sales network extends throughout many cities. At 
this stage, there is a logistics department to deal with the goods distribution of the company, and "factory - Distribution Centre - customer" logistics organization mode was used in the system.

At present, the company receives a high level of customer orders for distribution resulting in high logistics cost and difficult market management. The life cycle of electronic products is short, and the renewal speed is relatively fast. Therefore, in order to flexibly respond to the change of market and customer demand, the company plans to improve the efficiency of logistics distribution and customer service levels using the VMI mode.

\subsection{Data collection}

In this case, there are twenty-one customers and two depots. The goods are sent from the factory to the Distribution Centre (DC), and then after separation and packaging, goods will be sent from the DC to all customers. The coordination of the factory, DC, depots and customers are standardized, as shown in Table III.

Table III: Standardization coordination.

\begin{tabular}{|l|l|l|l|}
\hline Factory & $(0.60,0.40)$ & $\mathrm{C} 10$ & $(0.26,0.34)$ \\
\hline Distribution Centre & $(0.58,0.49)$ & $\mathrm{C} 11$ & $(0.80,0.68)$ \\
\hline Depot1 & $(0.26,0.23)$ & $\mathrm{C} 12$ & $(0.03,0.14)$ \\
\hline Depot2 & $(0.42,0.80)$ & C13 & $(0.93,0.72)$ \\
\hline C1 & $(0.26,0.68)$ & C14 & $(0.73,0.11)$ \\
\hline C2 & $(0.71,0.37)$ & C15 & $(0.49,0.65)$ \\
\hline C3 & $(0.22,0.99)$ & C16 & $(0.59,0.62)$ \\
\hline C4 & $(0.12,0.04)$ & C17 & $(0.24,0.78)$ \\
\hline C5 & $(0.30,0.89)$ & C18 & $(0.46,0.72)$ \\
\hline C6 & $(0.32,0.91)$ & C19 & $(0.96,0.90)$ \\
\hline C7 & $(0.41,0.49)$ & C20 & $(0.55,0.89)$ \\
\hline C8 & $(0.51,0.10)$ & C21 & $(0.52,0.33)$ \\
\hline C9 & $(0.09,0.26)$ & & \\
\hline
\end{tabular}

Normally, the life cycle of electronic products is short. Three kinds of electronic products (A, B, C) of the company are chosen as an example. The life cycle of these products just averages twelve months. Each life cycle can be divided into three parts; the introduction period from the first month to the third month, the growth period from the fourth month to the sixth month, and the mature period from the seventh month to the twelfth month. The demand of each customer is known.

The other parameters are as follows:

(1) The weight of product A is $0.5 \mathrm{~kg}$, the weight of product $\mathrm{B}$ is $0.8 \mathrm{~kg}$, and the weight of product $\mathrm{C}$ is $0.3 \mathrm{~kg}$.

(2) The maximum load of the vehicle is 10 tons, and the average running speed is $50 \mathrm{~km} / \mathrm{h}$.

(3) The fixed cost for each shipment from the factory to the DC is 200 , and the transportation cost is 2 .

(4) The fixed cost for each distribution of the DC is 150, and the fare between the DC and the customers is 1 .

(5) The starting cost of each vehicle is 100.

(6) The storage costs of all three products are all 50.

\subsection{Calculation result}

Not considering the time window constraint and the life cycle, the distribution route can be determined as follows: 
Route1: Depot1-DC-C7-C10-C9-C12-C4-Depot1.

Route2: Depot1-DC-C21-C2-C14-C8-Depot1.

Route3: Depot2-DC-C1-C17-C3-C5-C6-C20-Depot2.

Route4: Depot2-DC-C19-C13-C11-C16-C15-C18-Depot2.

The schematic diagram of the routes is shown in Fig. 6.

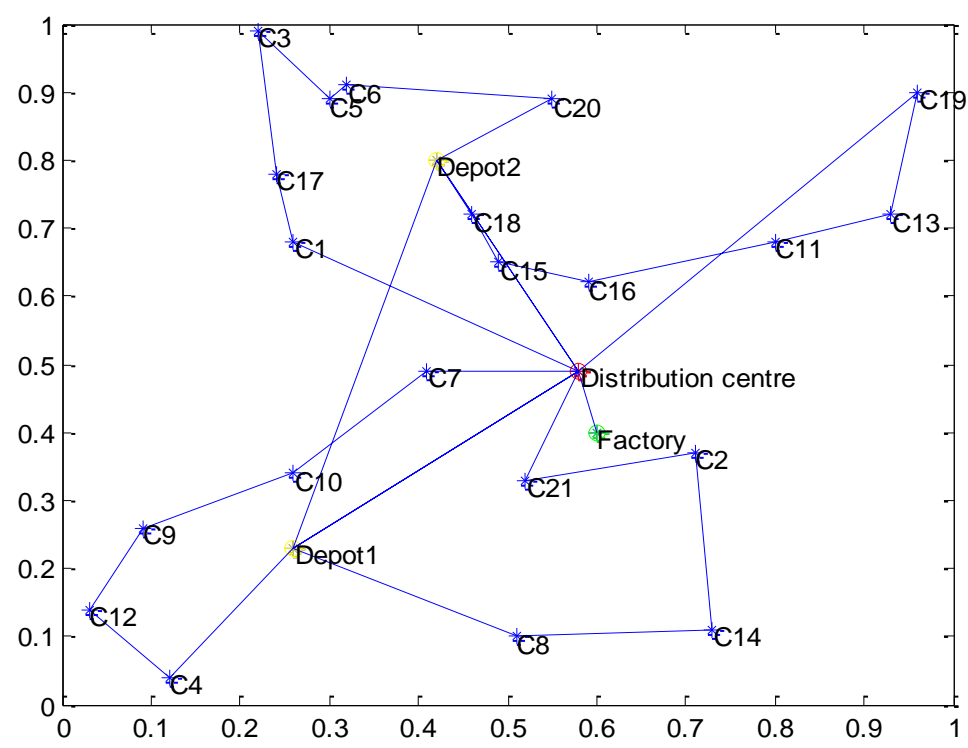

Figure 6: Schematic diagram of the routes.

In Fig. 6, the green point indicates the factory, the red point represent the DC, and the yellow points represent depots. Considering the time window constraint and life cycle, the distribution line is shown in Table IV.

Table IV: Distribution route considering time window constraint and life cycle.

\begin{tabular}{|l|l|}
\hline & Period 1 \\
\hline Route 1 & D1-DC-C7-C10-C9-C12-C4-D1 \\
\hline Route 2 & D1-DC-C2-C14-C21-C8-D1 \\
\hline Route 3 & D2-DC-C1-C17-C5-C6-C3-D2 \\
\hline Route 4 & D2-DC-C16-C20-C18-C15-D2 \\
\hline Route 5 & D2-DC-C11-C13-C19-D2 \\
\hline & Period 2 \\
\hline Route 1 & D1-DC-C7-C10-C21-D1 \\
\hline Route 2 & D1-DC-C9-C12-C4-D1 \\
\hline Route 3 & D1-DC-C2-C14-C8-D1 \\
\hline Route 4 & D2-DC-C1-C16-C15-C18-D2 \\
\hline Route 5 & D2-DC-C20-C6-C5-C3-C17-D2 \\
\hline Route 6 & D2-DC-C11-C13-C19-D2 \\
\hline & Period 3 \\
\hline Route 1 & D1-DC-C2-C21-C10-D1 \\
\hline Route 2 & D1-DC-C9-C12-C4-D1 \\
\hline Route 3 & D1-DC-C14-C8-D1 \\
\hline Route 4 & D2-DC-C7-C1-C17-D2 \\
\hline Route 5 & D2-DC-C3-C5-C6-D2 \\
\hline Route 6 & D2-DC-C16-C15-C18-D2 \\
\hline Route 7 & D2-DC-C11-C20-D2 \\
\hline Route 8 & D2-DC-C13-C19-D2 \\
\hline
\end{tabular}


From periods 1 to 3 , the demands of products are increasing resulting in adjustment of distribution line and increasing demand for vehicles.

\section{CONCLUSION}

In this paper, a novel mathematical model is presented to study a multi-product multi-period inventory routing problem with time window constrains. The logistics system is composed of one supplier and multiple customers. The inventory cost and distribution cost of the logistics system are analysed. A joint optimization model of inventory and distribution is established, which aims at minimizing the total cost. It also discusses the different distribution strategies in the different stages of the life cycle, as well as the distribution strategy with time window constraints.

In this study, both inventory costs and distribution costs are considered in the logistics system, and an improved fuzzy genetic algorithm is proposed to solve the optimization model of IRP for multi-products in multi-periods with time constrains. It has been proved that the algorithm is a very efficient approach for the IRPs. The effectiveness of the proposed algorithm and the optimization model are demonstrated through computational experiments simulation. The results show that the model and algorithm can solve practical problems, and has promising promotional prospects.

\section{REFERENCES}

[1] Chung, C.-J.; Wee, H.-M. (2008). Green-component life-cycle value on design and reverse manufacturing in semi-closed supply chain, International Journal of Production Economics, Vol. 113, No. 2, 528-545, doi:10.1016/j.ijpe.2007.10.020

[2] Zhu, Q.; Sarkis, J.; Lai, K.-H. (2008). Confirmation of a measurement model for green supply chain management practices implementation, International Journal of Production Economics, Vol. 111, No. 2, 261-273, doi:10.1016/j.ijpe.2006.11.029

[3] Lin, R.-J.; Chen, R.-H., Nguyen, T.-H. (2011). Green supply chain management performance in automobile manufacturing industry under uncertainty, Procedia - Social and Behavioral Sciences, Vol. 25, 233-245, doi:10.1016/j.sbspro.2011.10.544

[4] Wang, X.; Chan, H. K.; Yee, R. W. Y.; Diaz-Rainey, I. (2012). A two-stage fuzzy-AHP model for risk assessment of implementing green initiatives in the fashion supply chain, International Journal of Production Economics, Vol. 135, No. 2, 595-606, doi:10.1016/j.ijpe.2011.03.021

[5] Diabat, A.; Govindan, K. (2011). An analysis of the drivers affecting the implementation of green supply chain management, Resources, Conservation and Recycling, Vol. 55, No. 6, 659-667, doi:10.1016/j.resconrec.2010.12.002

[6] Wang, F.; Lai, X.; Shi, N. (2011). A multi-objective optimization for green supply chain network design, Decision Support Systems, Vol. 51, No. 2, 262-269, doi:10.1016/j.dss.2010.11.020

[7] Zhu, Q.; Sarkis, J. (2004). Relationships between operational practices and performance among early adopters of green supply chain management practices in Chinese manufacturing enterprises, Journal of Operations Management, Vol. 22, No. 3, 265-289, doi:10.1016/j.jom.2004.01.005

[8] Eltayeb, T. K.; Zailani, S.; Ramayah, T. (2011). Green supply chain initiatives among certified companies in Malaysia and environmental sustainability: Investigating the outcomes, Resources, Conservation and Recycling, Vol. 55, No. 5, 495-506, doi:10.1016/j.resconrec.2010.09.003

[9] Srivastava, S. K. (2007). Green supply chain management: A state-of-the-art literature review, International Journal of Management Reviews, Vol. 9, No. 1, 53-80, doi:10.1111/ j.1468-2370.2007.00202.x

[10] Sheu, J.-B. (2008). Green supply chain management, reverse logistics and nuclear power generation, Transportation Research Part E: Logistics and Transportation Review, Vol. 44, No. 1, 19-46, doi:10.1016/j.tre.2006.06.001 
Xiao, Rao: Multi-Product Multi-Period Inventory Routing Optimization with Time Window ...

[11] Bai, C.; Sarkis, J. (2010). Green supplier development: analytical evaluation using rough set theory, Journal of Cleaner Production, Vol. 18, No. 12, 1200-1210, doi:10.1016/ j.jclepro.2010.01.016

[12] Yeh,W.-C.; Chuang, M.-C. (2011). Using multi-objective genetic algorithm for partner selection in green supply chain problems, Expert Systems with Applications, Vol. 38, No. 4, 4244-4253, doi:10.1016/j.eswa.2010.09.091

[13] Dekker, R.; Bloemhof, J.; Mallidis, I. (2012). Operations research for green logistics - An overview of aspects, issues, contributions and challenges, European Journal of Operational Research, Vol. 219, No. 3, 671-679, doi:10.1016/j.ejor.2011.11.010

[14] Moin, N. H.; Salhi, S.; Aziz, N. A. B. (2011). An efficient hybrid genetic algorithm for the multi-product multi-period inventory routing problem, International Journal of Production Economics, Vol. 133, No. 1, 334-343, doi:10.1016/j.ijpe.2010.06.012

[15] Bertazzi, L.; Speranza, M. G. (2002). Continuous and discrete shipping strategies for the single link problem, Transportation Science, Vol. 36, No. 3, 314-325, doi:10.1287/trsc.36.3.314.7828

[16] Sindhuchao, S.; Romeijn, H. E.; Akcali, E.; Boondiskulchok, R. (2005). An integrated inventory-routing system for multi-item joint replenishment with limited vehicle capacity, Journal of Global Optimization, Vol. 32, No. 1, 93-118, doi:10.1007/s10898-004-5908-0

[17] Archetti, C.; Bertazzi, L.; Laporte, G.; Speranza, M. G. (2007). A branch-and-cut algorithm for a vendor-managed inventory-routing problem, Transportation Science, Vol. 41, No. 3, 382-391, doi: $10.1287 /$ trsc. 1060.0188

[18] Huang, S. H.; Lin, P.-C. (2010). A modified ant colony optimization algorithm for multi-item inventory routing problems with demand uncertainty, Transportation Research Part E: Logistics and Transportation Review, Vol. 46, No. 5, 598-611, doi:10.1016/j.tre.2010.01.006

[19] Persson, J. A.; Gothe-Lundgren, M. (2005). Shipment planning at oil refineries using column generation and valid inequalities, European Journal of Operational Research, Vol. 163, No. 3, 631-652, doi:10.1016/j.ejor.2004.02.008

[20] Kleywegt, A. J.; Nori, V. S.; Savelsbergh, M. W. P. (2002). The stochastic inventory routing problem with direct deliveries, Transportation Science, Vol. 36, No. 1, 94-118, doi:10.1287/ trsc.36.1.94.574

[21] Kleywegt, A. J.; Nori, V. S.; Savelsbergh, M. W. P. (2004). Dynamic programming approximations for a stochastic inventory routing problem, Transportation Science, Vol. 38, No. 1, 42-70, doi: $10.1287 /$ trsc. 1030.0041

[22] Bertazzi, L.; Bosco, A.; Guerriero, F.; Laganà, D. (2013). A stochastic inventory routing problem with stock-out, Transportation Research Part C: Emerging Technologies, Vol. 27, 89-107, doi:10.1016/j.trc.2011.06.003

[23] Chen, Y. M.; Lin, C.-T. (2009). A coordinated approach to hedge the risks in stochastic inventory-routing problem, Computers \& Industrial Engineering, Vol. 56, No. 3, 1095-1112, doi:10.1016/j.cie.2008.09.044

[24] Mishra, B. K.; Raghunathan, S. (2004). Retailer- vs. vendor-managed inventory and brand competition, Management Science, Vol. 50, No. 4, 445-457, doi:10.1287/mnsc.1030.0174

[25] Nonas, L. M., Jornsten, K. (2005). Heuristics in the multi-location inventory system with transshipments, Kotzab, H.; Seuring, S.; Muller, M.; Reiner, G. (Eds.), Research Methodologies in Supply Chain Management, Physica-Verlag HD, Heidelberg, 509-524, doi:10.1007/ 3-7908-1636-1 33

[26] Nonas, L. M.; Jornsten, K. (2007). Optimal solution in the multi-location inventory system with transshipments, Journal of Mathematical Modelling and Algorithms, Vol. 6, No. 1, 47-75, doi:10.1007/s10852-006-9049-y

[27] Coelho, L. C.; Cordeau, J.-F.; Laporte, G. (2012). The inventory-routing problem with transshipment, Computers \& Operations Research, Vol. 39, No. 11, 2537-2548, doi:10.1016/ j.cor.2011.12.020

[28] Thomke, S.; von Hippel, E. (2002). Customers as innovators: a new way to create value, Harvard Business Review, Vol. 80, No. 4, 74-81

[29] Federgruen, A.; Zipkin, P. (1984). A combined vehicle routing and inventory allocation problem, Operations Research, Vol. 32, No. 5, 1019-1037, doi:10.1287/opre.32.5.1019 
[30] Burns, L. D.; Hall, R. W.; Blumenfeld, D. E.; Daganzo, C. F. (1985). Distribution strategies that minimize transportation and inventory costs, Operations Research, Vol. 33, No. 3, 469-490, doi:10.1287/opre.33.3.469

[31] Anily, S.; Federgruen, A. (1990). One warehouse multiple retailer systems with vehicle routing costs, Management Science, Vol. 36, No. 1, 92-114, doi:10.1287/mnsc.36.1.92

[32] Ernst, R.; Pyke, D. F. (1993). Optimal base stock policies and truck capacity in a two-echelon system, Naval Research Logistics, Vol. 40, No. 7, 879-903, doi:10.1002/1520-6750(199312)40:7 $\leq 879::$ AID-NAV3220400703>3.0.CO;2-0

[33] Chandra, P.; Fisher, M. L. (1997). Coordination of production and distribution planning, European Journal of Operational Research, Vol. 72, No. 3, 503-517, doi:10.1016/ 0377-2217(94)90419-7

[34] Speranza, M. G.; Ukovich, W. (1997). Minimizing transportation and inventory costs for several products on a single link, Operations Research, Vol. 42, No. 5, 879-894, doi:10.1287/ opre.42.5.879

[35] Viswanathan, S.; Mathur, K. (1997). Integrating routing and inventory decisions in one-warehouse multiretailer multiproduct distribution systems, Management Science, Vol. 43, No. 3, 294-312, doi:10.1287/mnsc.43.3.294

[36] Herer, Y.; Roundy, R. (1997). Heuristics for a one-warehouse multiretailer distribution problem with performance bounds, Operations Research, Vol. 45, No. 1, 102-115, doi:10.1287/ opre.45.1.102 